\title{
Gastric Glomus Tumor
}

National Cancer Institute

\section{Source}

National Cancer Institute. Gastric Glomus Tumor. NCI Thesaurus. Code C95900.

A rare glomus tumor that arises from the stomach. It is seen in adults, especially women.

The majority of cases follow a benign clinical course. 